\title{
ERRATUM
}

\section{Erratum to: Prevalence of axial symptoms after posterior cervical decompression: a meta-analysis}

\author{
Miao Wang ${ }^{1}$ Xiao Ji Luo ${ }^{1} \cdot$ Qian Xing Deng ${ }^{1} \cdot$ Jia Hong Li $^{2} \cdot$ Nan Wang ${ }^{1}$
}

Received: 7 April 2016/Revised: 7 April 2016/Accepted: 7 April 2016/Published online: 13 April 2016

(c) Springer-Verlag Berlin Heidelberg 2016

\section{Erratum to: Eur Spine J}

\section{DOI 10.1007/s00586-016-4524-2}

An error has occurred in "Gender proportion" and "Pre-

operative average age" part of Table 2 .

The correct part of Table 2 is:

Table 2 Stratified meta-analysis of the prevalence of AS after cervical posterior decompression

\begin{tabular}{|c|c|c|c|c|c|c|c|}
\hline \multirow[t]{2}{*}{ Subgroups } & \multirow[t]{2}{*}{ No. of studies } & \multirow[t]{2}{*}{ No. of total patients } & \multirow[t]{2}{*}{ No. of AS } & \multirow[t]{2}{*}{ Pooled prevalence $(\%)$} & \multirow[t]{2}{*}{$95 \%$ CI } & \multicolumn{2}{|c|}{ Heterogeneity test } \\
\hline & & & & & & $I^{2}(\%) Q$ test & $P$ value \\
\hline \multicolumn{8}{|l|}{ Gender proportion } \\
\hline Male/female $>3$ & 8 & 412 & 84 & 20 & $14-26$ & 63.8 & 0.007 \\
\hline $2<$ male/female $<3$ & 15 & 1198 & 304 & 24 & $19-30$ & 80.8 & $<0.001$ \\
\hline $1 \leq$ male/female $<2$ & 15 & 1111 & 429 & 28 & $23-32$ & 87.1 & $<0.001$ \\
\hline \multicolumn{8}{|l|}{ Preoperative average age } \\
\hline Average age $>60$ & 18 & 1148 & 266 & 21 & $16-27$ & 80.6 & $<0.001$ \\
\hline Average age $<60$ & 18 & 1359 & 473 & 27 & $23-32$ & 86.5 & $<0.001$ \\
\hline
\end{tabular}

No number, $C I$ confidential interval, $A S$ axial symptoms

The online version of the original article can be found under doi:10.1007/s00586-016-4524-2.

Xiao Ji Luo

Mrluo1977@163.com

1 Department of Spine Surgery, The First Affiliated Hospital of Chongqing Medical University, 1\# Youyi Street, Chongqing 400016, People's Republic of China

2 University-Town of Chongqing Medical University, 55\# Da Xue Cheng Street, Chongqing 401331, People's Republic of China 